\title{
Primary education degree programs in Alicante, Barcelona and Helsinki: Could the differences in the mathematical knowledge of incoming students be explained by the access criteria?
}

\author{
Núria Gorgorió ${ }^{1}$, Lluís Albarracín ${ }^{1}$, Anu Laine ${ }^{2}$ and Salvador Llinares ${ }^{3}$ \\ 1 Universitat Autònoma de Barcelona, Catalonia, Spain \\ 2 University of Helsinki, Finland \\ ${ }^{3}$ Universidad de Alicante, Spain
}

\begin{abstract}
This perspective paper draws on the interest in ensuring that students who enter primary teacher training programs have a solid background knowledge of mathematics. We describe the access criteria and requirements for admission to the primary education degree programs at the Universidad de Alicante and Universitat Autònoma de Barcelona, in Spain, and the University of Helsinki, in Finland. We present the results of an evaluation of the mathematical knowledge that students bring to their education as teachers at these three institutions. The results show that in each program, the subgroup of students who had followed the longer track of mathematics courses scored significantly higher on the mathematical test, although this was no longer as clear when we compared across universities. We also found that the students who had taken the mathematics section of the entrance examination or the matriculation examination scored higher on the test than those from the same program who had not, but this tendency broke down when cross-university comparisons were made. We also explored how the cap set on the number of students admitted to the three programs - this being the most striking difference in the admission policies - could be an explanatory variable for these discrepancies. The comparison between universities leads us to hypothesize that expecting applicants to have met certain requirements in their academic trajectories prior to university entrance and adjusting the cap set on the number of places could ensure a better mastery of mathematical knowledge among those students admitted to the Spanish programs.
\end{abstract}

\author{
ARTICLE DETAILS \\ LUMAT General Issue \\ Vol 9 No 1 (2021), 174-207 \\ Received 14 December 2020 \\ Accepted 16 March 2021 \\ Published 6 April 2021 \\ Pages: 34 \\ References: 25 \\ Correspondence: \\ nuria.gorgorio@uab.cat \\ https://doi.org/10.31129/ \\ LUMAT.9.1.1468
}

Keywords: primary teacher education, university access criteria, university admission requirements, mathematical knowledge, background mathematical knowledge

\section{Introduction}

It is the responsibility of education degree programs to prepare quality teachers to serve society. Given this responsibility, such programs must have valid and reliable measures for screening candidates. The admission requirements of these programs should include an assessment of the following: the candidates' prior knowledge of the content of the different subjects they will later have to teach; their reasoning, problem-solving and critical thinking skills; their adherence to social ethics; and their 
dispositions to teaching (Miller-Levy, Taylor, and Hawke, 2014).

As educators of mathematics teachers, we have no doubt about the importance of primary teachers being sufficiently prepared to help children start growing mathematically. However, several studies have shown that many prospective teachers are admitted to and graduate from teacher education programs with insufficient knowledge to teach mathematics effectively (Beswisk and Goos, 2012; Hine, 2015; Ingram and Linsell, 2014; Lo and Luo, 2012; Norton, 2018; Tatto et al., 2008 and Qian and Youngs, 2016). In our paper, we focus on the evaluation of students' mathematical content knowledge at the beginning of primary education degree programs, taking as variables the distinct criteria and admission requirements of the programs.

Few studies address the characterization of the mathematical knowledge taken as a starting point on primary education degree programs or how far the admitted students' background mathematical knowledge is from this starting point. Furthermore, we have no knowledge of studies, except those carried out by our own research group (Gorgorió and Albarracín, 2019; Gorgorió, Albarracín, and Laine, 2019), that analyze possible relationships between the background mathematical knowledge of those enrolling on a primary education degree program and the screening criteria under which they were admitted to the programs. Our research at two universities in Spain, the Universidad de Alicante and the Universitat Autònoma de Barcelona, and one university in Finland, the University of Helsinki, was intended to provide an initial contribution to this analysis. The purpose of this study was to explore whether we can build a hypothesis about how changing admission criteria and requirements could lead to an improvement in the initial mathematical knowledge of students entering primary teacher training degrees in Spain.

Little has been accomplished in terms of determining how the institutional characteristics and national context in which teacher education takes place, together with the students' individual characteristics (Blömeke and Delaney, 2012), could influence the development of mathematical knowledge for teaching during teacher education. Comparative international studies focus on the organization, curriculum, processes, and results of teacher education (Li, 2012; Tatto et al., 2008), examining the structure and characteristics of programs and the knowledge and beliefs of student teachers at the end of their preparation (Blömeke and Delaney, 2012). Even less attention has been paid to the criteria and requirements for admission to teacher education programs, even though these are factors - together with the quality of 
learning opportunities and the methods by which student teachers are taught - that influence the development of their mathematical knowledge for teaching.

One of the characteristics to which little attention has been paid is the mathematical knowledge that students bring to teacher education programs, and this despite the fact that their background mathematical knowledge should be considered a powerful predictor of their success on such programs in terms of the development of mathematical knowledge for teaching. While studies like the Teacher Education and Development Study in Mathematics TEDS-M (Tatto et al., 2008) inform us about the quality of teacher education programs, and the mathematical knowledge that students have at the end of their teacher education, they provide us with less information about the entry requirements for teacher education programs, particularly regarding prior mathematical knowledge.

In their analysis of how opportunities to learn on teacher education programs influence future primary teachers' mathematics knowledge, Qian and Young (2016) suggest the need to account for selection effects within and across countries when investigating candidates' knowledge. However, the assessment of the mathematical knowledge of program applicants, either as a precondition for admission or for diagnostic and formative purposes, has rarely been the subject of research and, for the most part, the few studies that examine the topic have essentially limited themselves to describing the knowledge that students demonstrate (Linsell and Anakin, 2012). Moreover, exactly what prior mathematical knowledge should be considered desirable and what theories and methods might be used to characterize it has so far only been spelled out rather tentatively.

The lack of theoretical and methodological support implies that the evaluation of the mathematical background of students by teacher educators is currently a rather challenging undertaking (Linsell and Anakin, 2012), which is further hampered by a scarcity of research on the relationship between institutional criteria and admission requirements and the mathematical knowledge with which students enroll on the programs. This absence of a thorough theoretical debate about what constitutes desirable prior knowledge in students entering a teaching program runs parallel with the coexistence of multiple models for admission.

Admission criteria and entrance requirements, which differ across countries, reflecting both their social and cultural contexts, contribute to delineate candidates' individual characteristics, thus conditioning the opportunities to learn from which they can benefit. Comparative studies between countries that include an assessment 
of the prior knowledge that students bring to teacher education programs could help to explain the differences in the subsequent development of their knowledge during and upon completion of these programs. The same would be true of any comparison of how universities in different countries go about deciding how many and which applicants will be granted admission. International comparisons focusing on the background mathematical knowledge of students initiating a primary education degree program and how it relates to admission criteria and requirements should make it possible to identify variables and issues that may remain unquestioned in national studies, providing the opportunity to go beyond the familiar.

In this study we explored the mathematical knowledge evidenced by a test administered to students admitted to three teacher-training programs, taking as variables different factors linked to the admission criteria and requirements. Our data came from two universities in Spain, the Universidad de Alicante - in the region of Valencia - and the Universitat Autònoma de Barcelona - in the region of Catalonia, and one university in Finland, the University of Helsinki. In both Spain and Finland, initial teacher education is university-based. At the time we collected our data, none of these institutions had access requirements to their primary education degree programs that explicitly addressed the mathematical knowledge of candidates, but they did have different general admission criteria and requirements that could favor applicants with more or less solid background mathematical knowledge.

By admission criteria, we mean those aspects that are taken into consideration when establishing recruitment policies, either from the point of view of the desired characteristics of candidates admitted or from the perspective of the costs and benefits of teacher education (Davies et al., 2016). The criteria might refer, for example, to prior training, to the candidate's personal characteristics, and his/her academic trajectory or age, among others. For each of these admission criteria, different requirements could be established as compulsory. Moreover, it is important to analyze whether the way in which the number of places on each of the programs is decided generates groups with different mathematical background knowledge.

The purpose of this research was to explore whether we could generate a hypothesis about how the modification of admission criteria and requirements might lead to an improvement in the initial mathematical knowledge of students enrolling for teacher training degrees in Spain. To this end, we engaged in a three-stage study where we worked on each stage to achieve a specific goal related to the general goal. It is interesting to note that the results obtained in each stage, by way of a response to 
the specific goal of that stage, suggested the need for the study undertaken in the following stage. The results corresponding to the third goal indicate the need for further work in this area of research.

With this idea in mind, the goals that guided the three stages were:

1. to study whether there were any significant differences between the three primary education degree programs as regards the background mathematical knowledge of admitted students;

2. to examine whether there were significant differences in the students' background mathematical knowledge between groups of students who have followed different academic mathematics trajectories - the mathematics courses selected during secondary school, or having taken the mathematics section of the matriculation examination or the university entrance examination - within or across the three institutions;

3. to explore whether changing the cap set on the number of students admitted to the Alicante and Barcelona programs, taking the program at Helsinki as a reference, could affect the observed differences between the background mathematical knowledge of the students at the different institutions.

To simplify the reading of the text, from now on, we will refer to the primary education degree programs at Alicante, Barcelona and Helsinki as ALI, BCN and HEL, respectively.

\section{Why Alicante, Barcelona and Helsinki?}

The proposal presented in this document derives from a real concern of a group of mathematics educators involved in the initial training of primary school teachers. The first two authors, lecturers on BCN, were members of the project "Estudi per a l'avaluació diagnòstica de les competències matemàtiques dels estudiants del grau en Educació Primària"1 - Study for the diagnostic evaluation of the mathematical competences of Primary Teaching degree's students, developed as part of a program to improve teacher training in Catalonia. The results obtained within the framework of this project prompted them to seek the collaboration of the other two authors, lecturers on ALI and HEL, for the reasons detailed below.

${ }^{1}$ Funding body: AGAUR, Agència de Gestió d'Ajuts Universitaris i de Recerca, 2014 ARMIF-00041, Generalitat de Catalunya. 
Over the last four decades, the training of primary school teachers in Spain has evolved towards their professionalization, abandoning an approach closer to vocational training in favor of university studies (Sancho-Gil, Sánchez-Valero, and Domingo-Coscollola, 2017). However, as a legacy of the period in which a craftoriented vision of teaching was predominant, access to primary education degree programs remains, in practice, almost universal, as will be seen when we describe the candidate selection process. In Spain, all university degree programs have the same general framework of admission requirements, which is mandated by the Spanish central government. Students are allocated to the degree of their choice based on their ranking in the final list of access scores. However, the number of places available for incoming students on ALI and BCN differs, as does the number of applicants, which can result in successful applicants with different academic profiles at both universities. For this reason, we considered that it was worth exploring whether there were any differences in the background mathematical knowledge of those students entering ALI and BCN.

Since the results of the first PISA Study were published in 2000, there has been widespread international recognition of the success of Finland's educational model. Though many factors no doubt contribute to this success, the most important is believed to be the quality and competence of its teachers (Sahlberg, 2011). In Finland, where the teaching profession is highly valued (Niemi, 2016), there are specific selection processes for access to teacher education programs, during which candidates must demonstrate strong academic abilities and a passion for teaching. Darling-Hammond (2017) establishes that the recruitment of highly capable candidates into high-quality teaching degree programs is one of the Finnish practices that might be considered a strategy for improving teaching. In Finland, the policies and admission requirements of primary teaching programs are different from those in Spain. However, at the time the data was collected for this study, no specific requirement in relation to mathematics was included in either case. Thus, when comparing ways to access teacher education programs, it seemed interesting to include one from Finland. Moreover, places on HEL are considerably more restricted than on ALI and BCN. Thus, we found it interesting to include HEL in the study.

Below, we describe the access requirements and criteria for admission to the primary teaching degree programs in Spain and Finland, and we trace how mathematics is or is not part of the admitted candidates' academic trajectories. 


\section{Admission to the primary education degree programs and the role of mathematics in the process}

In Spain, for admission to a primary teaching degree (4 years, 240 ECTS), students must have completed compulsory education (up to 16) - during which all of them will have received a minimum ${ }^{2}$ of 1050 hours of formal preparation in mathematics. From this point on, they access the degree program by taking one of two paths that are different from the standpoint of their mathematical education: a) either the science and technology track or the social sciences track of the Bachillerato (the two years of non-compulsory, pre-university secondary education, hereinafter referred to as the baccalaureate), during which students complete a mathematics course each year amounting to a minimum of 280 hours - under the rubrics Mathematics and Mathematics for Social Sciences respectively; or b) the humanities or arts tracks of the baccalaureate, or any vocational training cycle related to education, none of which include courses in mathematics. Therefore, only some of the students admitted to primary education degree programs will have studied mathematics beyond compulsory education.

Spanish universities admit candidates according to two factors: the number of places available to students on a particular degree program and their access score. To be admitted to a university degree program, baccalaureate graduates must pass the university entrance examinations (Pruebas de Acceso a la Universidad). Among other content, the Spanish university entrance examinations include four mandatory subject-area-specific papers and a fifth compulsory language paper in autonomous communities with their own language, which examines this co-official language. Examples are Catalan in Catalonia and Valencian in the Community of Valencia. For those who have completed a social sciences baccalaureate, one of the four compulsory papers is Mathematics for social sciences, while the mandatory exam for those completing a science and technology baccalaureate is entitled simply Mathematics. Students who have completed a vocational training cycle may also gain access to university, based exclusively on their grades, although they may decide to take some university entrance exam papers in the hope of raising their access score. Therefore, only some of the students admitted to primary education degree programs will have

\footnotetext{
${ }^{2}$ Catalonia and the Valencian Community have a certain degree of educational autonomy and this allows them some flexibility in defining their compulsory education programs, always on the basis of the national legal framework. This autonomy is reflected by the fact that the number of hours of mathematics taught may exceed the nationally established minimum.
} 
taken one of the two university entrance mathematics exams. On the other hand, in Spain the number of course places on the different university teacher education programs bears no relation to the number of teaching jobs in the market, and at the time that data was collected for this study, there was no specific requirement for admission to teacher education programs outside the universal procedure described above.

Despite the inflexibility of the Spanish system, which establishes general access criteria for all degrees at a national level, there is a loophole that makes it possible to introduce complementary criteria for admission to a particular degree in one or more institutions - the so-called personal aptitude tests (PAP). In this way, a university, when offering a particular degree program, may require applicants to pass a personal aptitude test as a complementary admission requirement. Thus, the only way to influence the selection of applicants for a particular degree is that the competent authorities of the Autonomous Community and the central government accept the personal aptitude tests as an additional requirement established by the university. Degrees in translation and interpreting, sports sciences and some foreign languages have socially recognized and accepted personal aptitude tests. At the time the data was recorded for this study, none of the Spanish teacher training programs required a pass in a personal aptitude test. However, in Catalonia, by agreement among all the public and private universities, a personal aptitude test consisting of a mathematics exam and a Catalan language exam was introduced in the 2017-2018 academic year for admission to their teacher training courses.

Finnish teachers - both primary and secondary school teachers - are required to have completed a master's program (300 ECTS). This requirement was introduced for primary teachers in 1979 (Niemi, 2012). The structure of primary and secondary education in Finland is similar to that in Spain. During primary and lower secondary education (age 16) all students receive a total of 1216 hours of formal education in mathematics. In upper secondary school, students can choose either an intermediate mathematics track (for a total of at least 228 hours) or an advanced mathematics track (for a total of at least 380 hours).

At the end of upper secondary education, students take the Finnish matriculation examination (Ylioppilastutkinto), which is the only national-level assessment in Finland. At the time the data was recorded, each examinee was required to take at least four papers, only one of them - their mother tongue, Finnish or Swedish, depending on the vehicle language at the candidate's school - being compulsory. The 
remaining three were chosen by the student, with the option of one paper in mathematics, either intermediate or advanced. Vocational school graduates may also gain admission to university, the amount of mathematics they have studied depending on the specific vocational track they have pursued. However, enrolling from vocational school to study teacher education at university is an exception.

In Finland, students have to apply to enroll on specific programs at universities. Applicants interested in a primary education degree must go through a special twophase application process. The first phase, for all applicants in Finland, involves taking an exam (the so-called VAKAVA test3) based on a set of education-related readings. Based on their performance in the VAKAVA test, some applicants pass on to the second phase, which involves taking a suitability test that assesses their appropriateness to work as a teacher, their motivation and study skills, and their commitment to completing the degree. The actual form and content of the suitability test may differ from one teacher education program to another. Each university in Finland decides on the number of new admissions in conjunction with the Ministry of Education. At HEL, about $10 \%$ of applicants are admitted annually to the primary teacher education program. Out of the students accepted in 2016-17, 48 students (40\%) were selected on the basis of the suitability test alone, and 72 students (60\%) were selected on the basis of the suitability test and their grades in the YLIO in four subjects - Finnish and three optional subjects.

From the perspective of our study, the Finnish matriculation examination and the Spanish university entrance examinations have comparable functions when considering students' academic trajectories in relation to mathematics. Neither the Spanish university entrance mathematics exams nor the Finnish matriculation mathematics exams are an unavoidable requirement for access to primary teaching degree programs. In both cases, taking the mathematics exam corresponds to a decision made at the time of completing upper-secondary school or entering the University, but this decision was not determined by any requirement of the system. Therefore, we regarded the Spanish university entrance examinations and the Finnish matriculation examination as equivalent variables when determining population groups in our study.

${ }^{3}$ See https://www.helsinki.fi/en/networks/vakava/about-vakava-0 


\section{The test}

The instrument we used to collect our data was a mathematics test designed previously as the pilot version of the specific complementary entrance examination in Catalonia mentioned above, prior to its implementation. This complementary entrance examination had been created for the administrative purpose of limiting access to the primary education degree programs in Catalan universities to those applicants who possessed a minimum mastery of mathematical knowledge and competence in the Catalan language. The test consisted of 25 open-answer questions that evaluated mathematical content knowledge related to the prescribed curriculum of the Spanish compulsory education system, namely Numbers and Arithmetic, Space and Shape, Relationships and Change, Magnitude and Measure, and Statistics and Randomness (see the appendix for the English version of the test). The weight given to each content area was deliberately linked to the weight given to them in actual practice in the school system. For most of the questions, students had to generate their own answers in order to avoid guessing or the substitution of the given options strategy. Solving the questions required an understanding of the concepts and procedures involved, and the results had to be interpreted within each problem's context.

The content and structure of the test had been defined by a panel of experts from four Catalan universities - among them the two first authors - within the framework of the above-mentioned study at the beginning of the second section. It was then reviewed by experts from the University of Helsinki - the third author -, Oxford Brookes University, and Linköping University as well as by the fourth author, thus also ensuring the construct validity of the instrument for our research purposes. The instrument was then piloted on three separate occasions by BCN students starting the primary teacher education program in the 2013-2014, 2014-2015 and 2015-2016 academic years, respectively. This confirmed the instrument's test-retest reliability and provided the authors with valuable feedback from the students, allowing, for instance, the correction of troublesome wording. It also allowed us to confirm the instrument's criterion-related validity by studying the correlation of the test results with the grades obtained in the mathematics course by this sample of first-year students on BCN (for a full description of the process, see Gorgorió and Albarracín, 2019). The test form also included several questions in which the student gave us information about the academic trajectory they had followed up to that point - which allowed us to infer their prior exposure to formal mathematics preparation - and 
about whether they had taken or not the mathematics section of the Spanish university entrance examinations or the Finnish matriculation examination YLIO.

Though the original version of the test was written in Catalan, Spanish and Finnish language versions were prepared by the authors of this paper who are native speakers of these languages and know the target culture. People's names and the activities described in the questions were adapted to the different contexts where necessary. Since the instrument was designed with the specific purpose of assessing the candidates' mathematical knowledge in order to regulate their access to teaching programs in Catalonia, we felt that it would be a valid tool to measure students' background mathematical knowledge. Given the uniformity of schooling in Spain, we felt that it would be valid to also use it with ALI students. Moreover, the curricular content reflected in the test also responds to the Finnish school curriculum. Thus, it could also supposedly be used with HEL students.

To test the reliability of the data obtained with the mathematics test, we calculated the Cronbach's alpha, both overall and for each campus, as an internal consistency estimate of the reliability of the test scores (see Table 1).

Table 1. Cronbach's alpha of test scores for each university

\begin{tabular}{ll}
\hline & Cronbach's alpha \\
\hline ALI & 0.7428 \\
BCN & 0.8157 \\
HEL & 0.8106 \\
Overall & 0.7925 \\
\hline
\end{tabular}

The results that we obtained were in all cases higher than the reference value of 0.7 , a suitable indicator of the internal consistency of the instrument, meaning that the different test questions were consistent in their evaluation, from the perspective of the national curriculum, of the mathematical knowledge with which the students arrived at the primary education degree programs. Thus, we regard the instrument as a reliable measure of background mathematical knowledge.

We used the test to evaluate the background mathematical knowledge of all the students who had begun the first year of ALI, BCN and HEL - in the 2016-2017 academic year. The test was completed by a total of 756 students - 386 on ALI, 254 on BCN and 116 on HEL - before they had started any mathematics or mathematics education courses. None of them were under 18 years of age, and our statistical treatment of the data allowed us to anonymize their answers in the test. Furthermore, 
we asked them for permission to use the answers they gave in the test as research material.

At each university, a regular class period was set aside for students to answer the 25-item test on a worksheet, without using a calculator and in a maximum time of 90 minutes. The answers were subsequently marked by mathematics teachers at the respective universities, who assigned 1 point when the answer was completely correct (meanings, calculations, units, etc.) and o points if it was not.

\section{Differences in performance between Alicante, Barcelona and Helsinki students}

Table 2 presents the basic statistics that describe the centrality and distribution of the scores in the test by the students at the three universities, the maximum possible score on the test being 25 points. Table 3 presents the results of a series of means comparison t-tests across the universities.

Table 2. Centrality and distribution of the test scores on ALI, BCN and HEL

\begin{tabular}{lccccccccc}
\hline Variable & $\mathbf{N}$ & Mean & SE Mean & StDev & Minimum & Q1 & Median & Q3 & Maximum \\
& & & & & & & & & \\
\hline ALI & 386 & 12.343 & 0.203 & 3.988 & 2 & 9 & 13 & 15 & 21 \\
BCN & 254 & 15.996 & 0.302 & 4.812 & 3 & 12 & 16 & 20 & 25 \\
HEL & 116 & 17.233 & 0.405 & 4.363 & 7 & 14 & 17.500 & 21 & 25 \\
\hline
\end{tabular}

Table 3. T- tests comparison of score means across universities

\begin{tabular}{lccc}
\hline & $\begin{array}{c}\text { Estimate for } \\
\text { Difference }\end{array}$ & $\begin{array}{c}\text { Confidence Interval } \\
\text { for difference (95\%) }\end{array}$ & p-value \\
\hline HEL vs. BCN & 1.237 & $(0.242 ; 2.232)$ & 0.015 \\
HEL vs. ALI & 4.889 & $(3.995 ; 5.784)$ & 0.000 \\
BCN vs. ALI & 3.653 & $(2.938 ; 4.368)$ & 0.000 \\
HEL vs. BCN+ALI & 3.440 & $(2.560 ; 4.319)$ & 0.000 \\
\hline
\end{tabular}

Thus, we can affirm (95\% confidence) that HEL students obtained better results in the test than BCN students, who in turn performed better than ALI students. 


\section{Students' prior academic trajectories and background mathematical knowledge}

\subsection{Trajectories that include mathematics courses and performance in the test}

As noted above, in Spain, after their compulsory schooling, and depending on the academic track they chose before entering university, students may well study no further mathematics at all. We, therefore, divided the two Spanish groups into two subgroups each, with students who had taken mathematics courses during their baccalaureate in one subgroup and those who had only studied mathematics during compulsory schooling in the other. In Finland, all students had taken mathematics courses during their compulsory education and also in upper secondary school, but they had to choose between either advanced or intermediate mathematics. We, therefore, split the HEL group into two subgroups, depending on whether they had taken advanced or intermediate mathematics.

Table 4 shows the percentage of students in each subgroup, the mean score on the test for each subgroup, and the standard deviation. Table 5 presents the results of the t-tests of comparisons of means of the scores of the two subgroups at each university.

Table 4. Percentage of students, at each university, according to the mathematics track they followed in post-compulsory secondary education, mean of test scores of each subgroup, and standard deviations

\begin{tabular}{llll}
\hline & $\begin{array}{l}\text { Percentage of students } \\
\text { in each subgroup }\end{array}$ & $\begin{array}{l}\text { Mean score (max. } \\
\text { 25) }\end{array}$ & $\begin{array}{l}\text { Standard } \\
\text { deviation }\end{array}$ \\
\hline ALI only compulsory maths & $40.67 \%$ & 10.990 & 4.000 \\
ALI baccalaureate maths & $59.33 \%$ & 13.271 & 3.715 \\
BCN only compulsory maths & $42.52 \%$ & 13.611 & 4.488 \\
BCN baccalaureate maths & $57.48 \%$ & 17.760 & 4.263 \\
HEL intermediate maths & $59.48 \%$ & 15.261 & 4.065 \\
HEL advanced maths & $40.52 \%$ & 20.128 & 2.960 \\
\hline
\end{tabular}

Table 5. T-test comparing mean scores of subgroups within each university, depending on the mathematics track in post-compulsory secondary education

\begin{tabular}{llll}
\hline & $\begin{array}{l}\text { Estimate for } \\
\text { difference }\end{array}$ & $\begin{array}{l}\text { Confidence interval } \\
\text { for difference (95\%) }\end{array}$ & p-value \\
\hline ALI only compulsory vs. ALI baccalaureate maths & -2.281 & $(-3.073 ;-1.489)$ & 0.000 \\
BCN only compulsory vs. BCN baccalaureate maths & -4.149 & $(-5.248 ;-3.050)$ & 0.000 \\
HEL intermediate vs. HEL advanced maths & -4.867 & $(-6.160 ;-3.575)$ & 0.000 \\
\hline
\end{tabular}


It can be seen that the subgroup of students at each university who had followed the longer and/or more intensive track of mathematics courses scored significantly higher on the test. However, as the courses are structured differently in Finland and Spain, the only quantitative variable for which we can infer comparable values between the three universities is the number of hours of mathematics taken by the students before accessing the primary education degree programs.

Table 6 shows the total number of hours of mathematics lessons received by the six subgroups during both compulsory and non-compulsory education, and also the total.

Table 6. Hours of mathematics received during their education by each subgroup

\begin{tabular}{lllll}
\hline \multicolumn{5}{c}{ Hours of mathematics } \\
\hline & & $\begin{array}{l}\text { Compulsory } \\
\text { education }\end{array}$ & $\begin{array}{l}\text { Post-compulsory } \\
\text { secondary education }\end{array}$ & Total \\
\hline \multirow{2}{*}{$\mathrm{ALI} \& \mathrm{BCN} N$} & $\mathrm{ALI} \& \mathrm{BCN}$ baccalaureate maths & \multirow{2}{*}{1050} & $\begin{array}{l}280 \text { (2 years) } \\
0(2 \text { years })\end{array}$ & 1330 \\
& $\mathrm{ALI} \& \mathrm{BCN}$ only compulsory maths & & $380-494$ (3 years) & $1596-1710$ \\
\multirow{2}{*}{$\mathrm{HEL}$} & $\mathrm{HEL}$ advanced maths & \multirow{2}{*}{1216} & $228-304$ (3 years) & $1444-1520$ \\
\hline
\end{tabular}

Taking into account the information presented in Table 5 and Table 6, we observe that at each university the group of students who had taken more hours of mathematics did significantly better on the test.

However, this does not hold true if we compare across universities. Table 7 , in which mean test scores by subgroup are ordered from highest to lowest and accompanied by the number of hours taken by this subgroup, shows that while the number of hours may justify differences in performance at each university, this assertion cannot be maintained across universities.

Table 7. Subgroups by hours of mathematics received during compulsory and post-compulsory secondary education, ordered by mean scores on the test

\begin{tabular}{lll}
\hline & $\begin{array}{l}\text { Mean test score } \\
\text { (max. 25) }\end{array}$ & $\begin{array}{l}\text { Number of hours of } \\
\text { mathematics received }\end{array}$ \\
\hline HEL advanced maths & 20.128 & $1596-1710$ \\
BCN baccalaureate maths & 17.760 & 1330 \\
HEL intermediate maths & 15.261 & $1444-1520$ \\
BCN only compulsory maths & 13.611 & 1050 \\
ALI baccalaureate maths & 13.271 & 1330 \\
ALI only compulsory maths & 10.990 & 1050 \\
\hline
\end{tabular}


Moreover, as regards the difference in performance between the Spanish universities, ALI and BCN, the t-tests of comparison of means show that the difference is significant across analogous subgroups, as shown in Table 8, despite the fact that the number of hours of mathematics received was identical.

Table 8. T-test of comparison of means of test scores of analogous subgroups from the two Spanish universities depending on the number of hours of mathematics received

\begin{tabular}{llll}
\hline & $\begin{array}{l}\text { Estimate for } \\
\text { difference }\end{array}$ & $\begin{array}{l}\text { Confidence interval } \\
\text { for difference (95\%) }\end{array}$ & p-value \\
\hline $\begin{array}{l}\text { BCN baccalaureate maths vs. } \\
\text { ALI baccalaureate maths }\end{array}$ & -4.489 & $(-5.335 ;-3.642)$ & 0.000 \\
$\begin{array}{l}\text { ALI only compulsory maths vs. } \\
\text { BCN only compulsory maths }\end{array}$ & -2.621 & $(-3.680 ;-1.562)$ & 0.000 \\
\hline
\end{tabular}

At this point, our results show that the influence of whether or not academic trajectories contain mathematical courses on background mathematical knowledge is more complex than it might appear at first glance.

\subsection{Having taken the mathematics section of the entrance or matriculation examination and performance in the test}

We wanted to know whether students who had taken the mathematics section of the Spanish university entrance examinations or the Finnish matriculation examination scored differently in the background mathematics knowledge test from those who had not. Therefore, we divided each university group into two subgroups depending on whether or not they had taken the mathematics section of the corresponding examination. For each university, Table 9 shows the proportion of students in each group and their scores in the test.

Table 9. Proportion of students who had taken the mathematics section of the PAU or YLIO or had not, and the mean of scores each subgroup obtained on the test, with standard deviation

\begin{tabular}{llll}
\hline & $\begin{array}{l}\text { Percentage of } \\
\text { students in } \\
\text { each subgroup }\end{array}$ & $\begin{array}{l}\text { Mean score } \\
\text { on the test } \\
\text { (max. 25) }\end{array}$ & $\begin{array}{l}\text { Standard } \\
\text { deviation }\end{array}$ \\
\hline ALI maths section of university entrance examinations & $60.88 \%$ & 13.204 & 3.842 \\
ALIN no maths section of university entrance examinations & $39.12 \%$ & 10.931 & 3.940 \\
BCN maths section of university entrance examinations & $62.20 \%$ & 17.623 & 4.830 \\
BCN no maths section of university entrance examinations & $37.80 \%$ & 13.589 & 4.239 \\
HEL maths section of matriculation examination & $75.86 \%$ & 18.420 & 3.868 \\
HEL no maths section of matriculation examination & $24.14 \%$ & 13.500 & 3.717 \\
\hline
\end{tabular}


Table 10 shows the results of a series of T-tests of comparison of means when looking for differences between these subgroups at each university.

Table 10. T-test comparing mean scores of subgroups within each university, depending on whether or not students had taken the mathematics section of the PAU or YLIO

\begin{tabular}{llll}
\hline & $\begin{array}{l}\text { Estimate for } \\
\text { difference }\end{array}$ & $\begin{array}{l}\text { Confidence interval } \\
\text { for difference (95\%) }\end{array}$ & p-value \\
\hline $\begin{array}{l}\text { ALIN no maths section vs. no maths section of } \\
\text { university entrance examinations }\end{array}$ & -2.273 & $(-3.072 ;-1.474)$ & 0.000 \\
$\begin{array}{l}\text { BCN no maths section vs. no maths section of } \\
\text { university entrance examinations }\end{array}$ & -4.033 & $(-5.175 ;-2.891)$ & 0.000 \\
$\begin{array}{l}\text { HEL no maths section vs. maths section of } \\
\text { matriculation examination }\end{array}$ & -4.920 & $(-6.559 ;-3.282)$ & 0.000 \\
\hline
\end{tabular}

The t-test results show (with a 95\% confidence level) that at each university, students who had taken a mathematics paper as part of their university entrance or matriculation examination scored significantly higher on the test than students who had not.

However, the scores obtained by the ALI and BCN subgroups of students who took the university entrance mathematics exam are significantly different, and this discrepancy also holds for those who did not take the university entrance mathematics exam (see Table 11).

Table 11. T-tests of comparison of mean scores of analogous subgroups from the two Spanish programs depending on whether students had taken the mathematics section of the PAU or had not

\begin{tabular}{llll}
\hline & $\begin{array}{l}\text { Estimate for } \\
\text { difference }\end{array}$ & $\begin{array}{l}\text { Confidence interval } \\
\text { for difference (95\%) }\end{array}$ & p-value \\
\hline $\begin{array}{l}\text { ALI math section vs. BCN maths section of } \\
\text { university entrance examinations }\end{array}$ & -4.419 & $(-5.322 ;-3.516)$ & 0.000 \\
$\begin{array}{l}\text { ALI no maths section vs. BCN no maths section of } \\
\text { university entrance examinations }\end{array}$ & -2.658 & $(-3.491 ;-1.825)$ & 0.000 \\
\hline
\end{tabular}

Overall, the results obtained by grouping the students according to their previous academic trajectory show that we should look for some variable that better explains the differences in performance between students on ALI, BCN and HEL and especially between ALI and BCN. 


\section{On how changing the cap set on the number of students admitted would have changed the observed differences in performance across universities}

There is a clear difference between the Finnish institution and the two Spanish ones regarding admission policies to primary education degree programs. While in Finland, the cap set on the number of students admitted is based on the number of teachers needed by the community, in Spain there is no explicit policy that regulates it. Moreover, the proportion of students admitted relative to the total number of applicants to ALI is clearly higher than the corresponding proportion to $\mathrm{BCN}$. To understand this difference in the proportions, the concept of the cut-off mark generated during the admission process of students to Spanish university courses must be taken into account. Students who apply to enroll for any particular program are ordered according to their university entrance exam mark, and as many students as there are available places on that program are admitted to it. The cut-off mark is the entrance exam mark of the student who occupies the last place among those admitted. In this way, the greater the proportion between the number of admitted students and the number of students who apply, the lower the cut-off mark. For the 2016-2017 academic year, the cut-off mark was 7.904 out of $14^{4}$ for ALI, while for BCN it was $8.758^{5}$.

In the following paragraphs, we analyze how a hypothetical reduction in the number of admitted candidates might close the gap observed between the results obtained for HEL, BCN and ALI in the mathematics test that we set. Thus, we establish, ex post facto, a reduction in the number of students whose test scores we now take as data. This allows us to discuss the possible effects that restricting the number of places might have on the test scores.

\footnotetext{
${ }^{4}$ Generalitat Valenciana. Informe 2016-2017. Servicio de Regulación Universitaria Dirección General de Universidad y Estudios Superiores. http://preinscripcionuniversitaria.edu.gva.es/docs/NotasCorte2016.pdf

${ }^{5}$ Consell Interuniversitari de Catalunya. Cut-off marks. 2nd selection June 2016, 22/07/2016.

http://universitatsirecerca.gencat.cat/web/ca/03_ambits_dactuacio/acces_i_admissio_a_la_universitat/.content/ac ces_i_admissio_a_la_universitat/preinscripcio_per_a_les_universitats_publiques_i_universitat_de_vic/llistes_d e_notes_de_tall_i_de_places_universitaries/documents/Notes-tall-2a-assignacio-21-07-16-JUNY -2016 .pdf
} 
We can get a rough idea of what the HEL cap set on available places means as compared to that for ALI and BCN by looking at the number of places in each institution relative to the total population of the area that the universities serve. The respective catchment areas are Finland for HEL and, in Spain, the Valencian Community for ALI and Catalonia for BCN. Table 12 shows this ratio for Finland, based on data from the 2016-2017 academic year, and compares it to analogous data for ALI and BCN and the two Spanish autonomous regions where they are located Valencia and Catalonia, respectively.

Table 12. Total population, students admitted to primary teacher education programs in the region/country in the 2016-17 academic year, number of inhabitants per student admitted, and number of students admitted to ALI, BCN and HEL

\begin{tabular}{lllll}
\hline & Population & $\begin{array}{l}\text { Students admitted } \\
\text { in 2016-2017 to the } \\
\text { teaching programs } \\
\text { in the } \\
\text { region/country }\end{array}$ & $\begin{array}{l}\text { Number of } \\
\text { inhabitants per } \\
\text { student } \\
\text { admitted }\end{array}$ & $\begin{array}{l}\text { Number of } \\
\text { students on } \\
\text { ALI, BCN and } \\
\text { HEL }\end{array}$ \\
\hline Valencia & $4932302^{\mathrm{a}}$ & $1750^{\mathrm{b}}$ & 2818 & $386(\mathrm{ALI})$ \\
Catalonia & $7453957^{\mathrm{c}}$ & $1920^{\mathrm{d}}$ & 3882 & $254(\mathrm{BCN})$ \\
Finland & $5509717^{\mathrm{e}}$ & $841^{2}$ & 6551 & $116(\mathrm{HEL})$ \\
\hline
\end{tabular}

a \& b Instituto Nacional de Estadística, June 2017:

http://www.ine.es/dynt3/inebase/es/index.htm?padre=1894\&capsel=1900

b Informe 2016_2017. Servicio de Regulación Universitaria. Dirección General de Universidad, Investigación y Ciencia. Generalitat Valenciana.

http://www.ceice.gva.es/documents/161863209/163489417/Informe+General+de+Preinscripci\%C3\%B3n+.pdf/7 3dafb19-6132-432a-847a-6da2687df874;jsessionid=3B35D14C840604C5287EA6C7CD0F3964

d Informes i estadístiques de la preinscripció universitària.

http://universitats.gencat.cat/ca/altres_pagines/informe_i_estadistiques/informes_i_estad_pre/

e Statistics Finland, August 2017: http://www.stat.fi/til/vamuu/2017/08/vamuu_2017_08_2017-09_

21_tie_001_en.html

For comparison, we take HEL as a reference since it is the program among the three studied that admits the fewest students. If we consider the number of students admitted to teacher training programs in Finland (841) and the number of Finns $(5,509,717)$, we obtain a ratio of $1: 6551$, i.e. in Finland one student is admitted for every 6551 inhabitants. Similarly, the ratios for ALI and BCN are calculated in relation to their corresponding catchment areas, the Valencian Community and Catalonia. Therefore, in Table 12 we can see that far fewer students were admitted to the primary teaching program in Finland than in either Spanish region, with a student to population ratio of 1:6551 as compared to 1:2818 and 1:3822. 
To simulate what would happen if an admissions policy as similarly restrictive as the one in Finland was applied at the Spanish institutions, we have to take the ratio of inhabitants per student admitted to the Finnish programs as a benchmark and adjust the number of students admitted to BCN and ALI to achieve the same proportion. To adjust the proportions to the Finnish ratio, we have to divide the number of students admitted to ALI by $6551 / 2818=2.32$ and the number of students admitted to BCN by $6551 / 3882=1.69$. Thus, hypothetically only 166 students $(386 / 2.32)$ would have been admitted to ALI and 150 students (254/1.69) to BCN.

Since individual scores on the test are available, we then select the 166 and 150 highest-scoring ALI and BCN students, respectively, to make up our new hypothetical groups. Descriptive data for these groups' test scores are shown in Table 13, alongside those of the original HEL group.

Table 13. Number of students in each group, highest and lowest score per group, mean of scores in each subgroup obtained on the test, with standard deviations when creating new groups adjusting the cap set on the number of students admitted

\begin{tabular}{llllll}
\hline & $\begin{array}{l}\text { Number } \\
\text { of } \\
\text { students }\end{array}$ & $\begin{array}{l}\text { Highest } \\
\text { student score } \\
\text { (max. 25) }\end{array}$ & $\begin{array}{l}\text { Lowest } \\
\text { student } \\
\text { score }\end{array}$ & $\begin{array}{l}\text { Mean score } \\
\text { for the group }\end{array}$ & $\begin{array}{l}\text { Standard } \\
\text { deviation }\end{array}$ \\
\hline ALI hypothetical new group & 166 & 21 & 13 & 15.979 & 2.120 \\
BCN hypothetical new group & 150 & 25 & 15 & 19.320 & 2.586 \\
HEL & 116 & 25 & 7 & 17.233 & 4.363 \\
\hline
\end{tabular}

That the standard deviations for the BCN and ALI hypothetical new groups are smaller is not surprising since the data was artificially trimmed. It is worth noting that the mean score achieved by the restricted BCN group is now significantly higher than the HEL mean score, the estimate for the difference being 2.087 and the confidence interval for the difference (95\%) being $(1.1916,2.9824)$ while the ALI mean score is still lower than the HEL mean score.

To simulate what would happen if we adjusted the ratio of students admitted across the two Spanish institutions, the number of ALI places would have to be reduced by a ratio of $3882 / 2818=1,378$, so that 280 students would be accepted (386 ALI students / 1.378). We present the descriptive data for BCN and ALI when adjusting the ratio in ALI to that of BCN, with 280 students, in Table 14. 
Table 14. Test score data for the top $280 \mathrm{ALI}$ students (ALI280) and BCN students

\begin{tabular}{lllll}
\hline & $\begin{array}{l}\text { Highest student } \\
\text { score (max. 25) }\end{array}$ & $\begin{array}{l}\text { Lowest } \\
\text { student score }\end{array}$ & $\begin{array}{l}\text { Mean score } \\
\text { for the group }\end{array}$ & $\begin{array}{l}\text { Standard } \\
\text { deviation }\end{array}$ \\
\hline $\begin{array}{l}\text { ALI adjusting the ratio to that of BCN } \\
\text { (280 students) }\end{array}$ & 21 & 10 & 14.205 & 2.826 \\
BCN & 25 & 3 & 15.996 & 4.812 \\
\hline
\end{tabular}

The table shows that despite this reduction, students in the reduced group of ALI still perform lower (1.791 out of 25) than BCN students, significant at 95\% since the difference cannot be less than 1.111.

\section{Discussion}

Our research assumes that the background mathematical knowledge that students bring to primary education degree programs plays a key role in their completing such programs with sufficient mathematical knowledge for teaching. In our study, we used a 25-item test to measure the mathematical knowledge of students enrolled on three of these programs, two in Spain and one in Finland, which had not yet begun any courses related to mathematics or mathematics education. We, therefore, regard their scores on this test as a legitimate index of their background mathematical knowledge prior to admission.

\subsection{Searching for explanatory variables for performance differences in the test}

In our study, we found that the performance of Finnish students was significantly better than that of Spanish students. The superior performance of HEL students may not surprise the reader because these results would seem to be consistent with the current prestige of the Finnish education system. However, BCN students also performed significantly better than ALI students, despite the fact that they shared the same general admission criteria and requirements at that time, and with the school curriculum being the same all over Spain. Here we identified a difference between the two Spanish institutions that required an explanation.

Our results also show that at each of the three universities the subgroup of students who had followed the more intense track of mathematics courses scored significantly higher on the background mathematical knowledge test. We could not make a direct quantitative comparison of the results obtained for ALI and BCN and those obtained for HEL since the mathematical tracks at Finnish upper-secondary are 
structured differently from those at the Spanish baccalaureate. In fact, the only quantitative variable for which we can infer comparable values at the three universities is the number of hours of mathematics taken by the students up to the moment of accessing university.

When we take into account the number of hours of mathematics received on comparing performance in the test, the results show that at each university the group of students who had taken more hours of mathematics did significantly better on the test. This suggests that the absolute number of hours of mathematics that students receive during their education is what determines average scores on the test. However, our data does not support this assumption if we compare across universities. The number of hours of mathematics received by all HEL students, even those who had only taken intermediate mathematics courses prior to university, is higher than the number of hours of mathematics received by students on ALI and BCN who had taken mathematics during their two pre-university years. Nevertheless, the second-ranking subgroup by mean score is the group on $\mathrm{BCN}$ that had taken mathematics during their baccalaureate, in fact receiving fewer hours of mathematics preparation than the intermediate mathematics HEL group.

We could justify this apparent discrepancy by arguing that student scores in this test are not only related to the number of hours of mathematics preparation but also linked to whether the way of working in the mathematics classroom is aligned or not with the emphasis encountered in the test questions, the greatest divergence in this regard possibly being an interest in real-life problem-solving as opposed to an interest in more formal mathematics. The verification of this hypothesis requires access to information that is unavailable to us.

However, the students on BCN who studied mathematics during their baccalaureate performed significantly better than the analogous subgroup of students on ALI, even if they took the same number of hours of mathematics. The same is true for the subgroups on BCN and ALI that had not studied mathematics during the baccalaureate. This significant difference in the results obtained by analogous groups on ALI and BCN, with the programs both admitting students taught in a system in which school mathematics education is quite uniform, is a striking discrepancy, and it demands an explanation.

The other variable that we considered in relation to the academic trajectory of students is whether they had taken the mathematics section as part of their university entrance examination in Spain, or as part of the Matriculation Examination in 
Finland. We observed that the students who had taken the mathematics section scored higher on our test than those from the same university who had not, though again, this tendency broke down when cross-university comparisons were made. Again, what is most striking is that, despite the uniformity of the requirements for admission to Spanish universities, the scores obtained by the ALI and BCN subgroups of students who took the PAU mathematics exam are significantly different, and this discrepancy also holds for those who did not take the PAU mathematics exam.

Therefore, our overarching conclusion regarding the students' academic trajectories in mathematics is that, although the variables considered in our study may explain the differences within each university, they do not explain the differences across universities. Furthermore, in the case of the two Spanish universities, there are clear discrepancies between our findings and what might be expected in a school system as uniform as the Spanish system is assumed to be.

\section{The cap set on the number of students admitted as explanatory variable}

As institutions that exist in different socio-cultural contexts, ALI, BCN and HEL are likely to exhibit important differences in their organization. Perhaps the most striking difference is the policy regarding the cap set on the number of students admitted. While in Finland this cap is based on the number of teachers that the community needs, in Spain there is no explicit policy that regulates it. Given the limited number of candidates admitted to HEL and the differences in admission rates between ALI and $\mathrm{BCN}$, we decided that it was worth evaluating the interaction between this restrictiveness in admission policy and the students' results in the background mathematical knowledge test. We are not saying that this is the only factor that might influence performance on the test, but it certainly deserves consideration.

On adjusting the cap set on students admitted to ALI and BCN by taking the cap on HEL as a reference, we observe that the mean score achieved by the restricted BCN group is significantly higher than the HEL mean score. The new difference between HEL and the reduced BCN group could be explained not only by the restriction on the number of students admitted but also because the questionnaire we worked with was bound to the Spanish context.

When introducing a similar restriction between the two Spanish institutions, we observe that the distance between the mean scores is reduced. Even so, BCN students continue to perform significantly better. This continuing difference, together with the discrepancies that we have pointed out in the differences between the scores for ALI 
and $\mathrm{BCN}$, could be explained by "competitiveness in the market". $\mathrm{BCN}$, given its geographical location and its academic prestige, competes strongly with the other five primary teaching degree programs offered by universities in the area. As a result, it is the first choice for many of the students, producing a greater reduction in the proportion of students admitted than that artificially created by the restrictions we can apply to our data. The confirmation of this hypothesis requires further research in itself.

\section{Conclusion}

To date, most studies discussing the mathematics component of the curriculum of primary education degree programs seem to assume that incoming students have already mastered a certain body of basic mathematical knowledge, when there is increasing evidence, at least in some countries, that they have not (Beswisk and Goos, 2012; Hine, 2015; Ingram and Linsell, 2014; Lo and Luo, 2012; Norton, 2018; Tatto et al., 2008; and Qian and Youngs, 2016). The studies of Arce, Marbán and Palop (2017), Buforn and Fernández (2014), Gutiérrez-Gutiérrez, Gómez and Rico (2016), Montes et al. (2015), Nortes and Nortes (2013), and Sáenz (2007) are some examples of research that has gathered evidence of limitations in the mathematical knowledge of students on primary teaching degree programs in Spain.

Our findings regarding the performance of the different groups of students allowed us to identify variables that tend to go unquestioned at a national level but which may have a considerable impact on the quality of primary education degree programs and their graduates. Variables such as the criteria according to which students are admitted to these programs or the number of places available on a particular program are defined at national level and shaped by the social and cultural context of the teaching institutions. How these criteria are established may influence the success of primary education degree programs because they have an impact on the extent of the mathematical knowledge that successful applicants will bring to the program. This is yet one more way in which social context may impact teacher education, albeit with a broader interpretation than that offered by Blömeke, Suhl, and Dörmann (2013).

We are aware that our research only addresses student performance from a quantitative perspective, leaving unstudied other individual and social variables that undoubtedly influence the academic profile of applicants admitted to the programs. There are several qualitative variables that distinguish the Finnish and Spanish 
institutional contexts. Among them, at an individual level, we find the different value ascribed to the mathematics grades achieved by applicants taking the matriculation examination in Finland and the entrance tests in Spain. Also, at an individual level, the consideration of the candidates' interest in and attitude to becoming teachers is different, something that can provide strong motivation to learn the content they will have to teach, such as mathematics, among other subjects. Thus, in Finland at present, among the students who reach the second stage of the selection process, $60 \%$ are selected only on the basis of their grades in four subjects in the matriculation examination (mother tongue, mathematics, another language and one subject from the humanities and natural sciences) and 40\% are selected only on the basis of their results in the VAKAVA, a test that reflects the candidates' attitude to studying to be a teacher and to the profession. The social status of teachers, which is very high in Finland, is a contextual social variable that may influence the previous ones.

In relation to mathematical knowledge, it is urgent to encourage a debate not only to establish what mathematical knowledge could legitimately constitute a prerequisite for admission to teacher education programs, but also to provide primary teaching programs with reliable instruments that can be used to determine whether applicants have a solid background knowledge of mathematics. While we wait for this debate to produce clear results, the findings of the present study suggest that two measures, in particular, might have a significant impact on the academic profile of students enrolling on the Spanish programs: on the one hand, changing the policy regarding the cap set on the number of students admitted to Spanish primary teaching degree programs and adjusting it to the number of teachers needed and, on the other hand, using screening criteria based on the results of a specific mathematics entrance test might have a significant impact on the academic profile of students enrolling on these programs. Furthermore, the pool of applicants could be limited by only allowing those who had passed the mathematics section of the university entrance examinations or completed a minimum number of mathematics courses at secondary school to apply in the first place. Any of these options would ensure a better mastery of mathematical knowledge at the start of the program.

In Spain, the number of places available on teacher training programs could be reduced, because nowadays there is an important segment of teacher training graduates who have an occupation other than teaching. In addition, the gap between the number of graduates and the number of new teachers needed each year could be narrowed down, as evidenced by the waiting lists for teaching positions. It would also 
be possible to introduce some additional selection criteria. We have already mentioned that, despite the inflexibility of the university entrance system in Spain, there is at least one way to influence the selection of applicants, which is through personal aptitude tests.

It could be argued that the introduction of a selective test of mathematical content as a requirement for admission to primary education degree programs would obviously have an economical cost. Nevertheless, it is clearly feasible to require applicants to have completed a minimum number of mathematics courses during secondary school or to have taken one or the other of the two options of the mathematics section of the national university entrance examination. Neither of these options would imply major changes in the university system since they would only affect admission requirements. Resistance to their implementation is likely to be less related to possible financial costs for the public education system than to a reluctance among administrators to raise what the general public might view as a new and specifically targeted obstacle to a teaching career. Overcoming such resistance to these measures may require highlighting the link between excellence in teacher education and the immense value that teachers can add to society as those in charge of the education of future generations.

We approached our research with the goal of finding out how the processes and criteria for the admission of candidates could have an impact on the mathematical knowledge of the students who enter teacher-training programs. Our study has identified variables that affect the profile of successful candidates. However, there is still a need to explore how these variables might influence the results obtained by students during their training as future teachers and, therefore, the quality of the programs. All told, this research only answers a few questions about admission to primary education degree programs, while raising many more.

\section{Acknowledgements}

This research was carried out in the framework of the project EDU2017-8247-R funded by Spanish Ministry of Science, Innovation and Universities. 


\section{References}

Arce, M., Marbán, J.M., \& Palop, B. (2017). Aproximación al conocimiento común del contenido matemático en estudiantes para maestro de primaria de nuevo ingreso desde la prueba de evaluación final de Educación Primaria. In J.M. Muñoz-Escolano, A. Arnal-Bailera, P. Beltrán-Pellicer, M.L. Callejo, \& J. Carrillo (Eds.), Investigación en Educación Matemática, $X X I$ (pp. 127-136). Zaragoza: SEIEM.

Beswisk, K., \& Goos, M. (2012). Measuring pre-service teachers' knowledge for teaching mathematics. Mathematics Teacher Education and Development, 14(2), 70-90. https://doi.org/10.1080/18117295.2019.1682777

Blömeke, S., \& Delaney, S. (2012). Assessment of teacher knowledge across countries: a review of the state of research. ZDM - The International Journal on Mathematics Education, 44(3), 223-247. https://doi.org/10.1007/s11858-012-0429-7

Blömeke, S., Suhl, U., \& Döhrmann, M. (2013). Assessing strengths and weaknesses of teacher knowledge in Asia, Eastern Europe, and Western Countries: Differential Item Functioning in TEDS-M. International Journal of Science and Mathematics Education, 11(4), 795-817. https://doi.org/10.1007/s10763-013-9413-0

Buforn, Á., \& Fernández, C. (2014). Conocimiento de Matemáticas Especializado de los estudiantes para maestro de primaria en relación al razonamiento proporcional. Bolema - Boletín de Educación Matemática, 28(48), 21-41. http://dx.doi.org/10.1590/1980-4415v28n48a02

Darling-Hammond, L. (2017). Teacher education around the world: What can we learn from international practice? European Journal of Teacher Education, 4O(3), 291-309. https://doi.org/10.1080/02619768.2017.1315399

Davies, P., Connolly, M., Nelson, J., Hulme, M., Kirkman, J., \& Greenway, C. (2016). 'Letting the right one in': Provider contexts for recruitment to initial teacher education in the United Kingdom. Teaching and Teacher Education, 60, 291-302. https://doi.org/10.1016/j.tate.2016.09.003

Gorgorió, N., \& Albarracin, L. (2019). El conocimiento matemático previo a la formación inicial de los maestros: necesidad y concreción de una prueba para su evaluación. In E. Badillo, N. Climent, C. Fernández, \& M. T. González (Eds.), Investigación sobre el profesor de matemáticas: formación, práctica de aula, conocimiento y competencia profesional (pp. 111-132). Salamanca: Ediciones Universidad Salamanca.

Gorgorió, N., Albarracín, L., \& Laine, A. (2019). Impact of access requirements on the mathematical knowledge of students admitted to Primary Teaching programs: a microcomparative study. In U. T. Jankvist, M. Van den Heuvel-Panhuizen, \& M. Veldhuis (Eds.), Proceedings of the Eleventh Congress of the European Society for Research in Mathematics Education (CERME11, February 6 - 10, 2019). (pp. 2031-2038). Freudenthal Group \& Freudenthal Institute, Utrecht University. https://hal.archives-ouvertes.fr/hal02421759/

Gutiérrez-Gutiérrez, A., Gómez, P., \& Rico, L. (2016). Conocimiento matemático sobre números y operaciones de los estudiantes de magisterio. Educación XXI, 19(1), 135-158. https://doi.org/10.5944/educxx1.15581

Hine, G. (2015). Strengthening pre-service teachers' mathematical content knowledge. Journal of University Teaching \& Learning, 12(4), 1-13. https://ro.uow.edu.au/jutlp/vol12/iss4/5

Ingram, N., \& Linsell, C. (2014). Foundation content knowledge: Pre-service teachers' attainment and affect. In J. Anderson, M. Cavanagh, \& A. Prescott (Eds.), Curriculum in focus: Research guided practice: Proceedings of the 37th annual conference of the Mathematics Education Research Group of Australasia (pp. 712-718). Sydney: MERGA. 
Li, Y. (2012). Mathematics teacher preparation examined in an international context: learning from the Teacher Education and Development Study in Mathematics (TEDS-M) and beyond. ZDM - The International Journal on Mathematics Education, 44(3), 367-370. https://doi.org/10.1007/s11858-012-0431-0

Linsell, C. \& Anakin, M. (2012). Diagnostic Assessment of Pre-Service Teachers' Mathematical Content Knowledge. Mathematics Teacher Education and Development, 14(2), 4-27.

Lo, JJ. \& Luo, F. J. (2012). Prospective elementary teachers' knowledge of fraction division. Journal of Mathematics Teacher Education, 15, 481-500. https://doi.org/10.1007/s10857012-9221-4

Miller-Levy, R., Taylor, D., \& Hawke, L. (2014). Maintaining the boundaries: Teacher preparation program admission criteria for screening quality candidates. Administrative Issues Journal: Education, Practice, and Research, 4(1), 40-49.

Montes, M.A., Contreras, L.C., Liñán, M.M., Muñoz-Catalán, M.C., Climent, N., \& Carrillo, J. (2015). Conocimiento de aritmética de futors maestros. Debilidades y fortalezas. Revista de Educación, 367, 36-62. https://doi.org/10.4438/1988-592X-RE-2015-367-282

Niemi, H. (2012). The societal factors contributing to education and schooling in Finland. In $\mathrm{H}$. Niemi, A. Toom and A. Kallioniemi (Eds.), Miracle of Education. The Principles and Practices of Teaching and Learning in Finnish Schools. (pp. 19-38). Rotterdam: Sense Publishing. https://doi.org/10.1007/978-94-6091-811-7_2

Nortes, A., \& Nortes, R. (2013). Formación inicial de maestros: un estudio en el dominio de las matemáticas. Profesorado: Revista de currículum y formación del profesorado, 17(3), 185-200. https://doi.org/10.4438/1988-592X-RE-2012-363-169

Norton, S. (2018). The relationship between mathematical content knowledge and mathematical pedagogical content knowledge of prospective primary teachers. Journal of Mathematics Teacher Education, 22, 489-514. https://doi.org/10.1007/s10857-018-9401-y

Qian, H., \& Youngs, P. (2016). The effect of teacher education programs on future elementary mathematics teachers' knowledge: a five-country analysis using TEDS-M data. Journal of Mathematics Teacher Education, 19(4), 371-396. https://doi.org/10.1007/s10857-0149297-0

Sahlberg, P. (2011). Finnish lessons: what can the world learn from educational change. New York, USA: Teacher College Press.

Sancho-Gil, J.M., Sánchez-Valero, J., \& Domingo-Coscollola, M. (2017). Research-based insights on initial teacher education in Spain. European Journal of Teacher Education, 4O(3), 310325. https://doi.org/10.1080/02619768.2017.1320388

Tatto, M.T., Schwille, J., Senk, S., Ingvarson, L., Peck, R., \& Rowley, G. (2008). Teacher Education and Development Study in Mathematics (TEDS-M): Policy, practice, and readiness to teach primary and secondary mathematics. Conceptual framework. East Lansing, MI: Teacher Education and Development International.

Sáenz, C. (2007). La competencia matemática (en el sentido PISA) de los futuros maestros. Enseñanza de las Ciencias, 25(3), 322-366. https://www.raco.cat/index.php/Ensenanza/article/view/87932 


\section{Appendix A}

\section{SURVEY OF BACKGROUND MATHEMATICAL KNOWLEDGE}

Answer the following questions. Write in the empty space how you ended up to your answer. You can use drawings, text, calculations...

1. Which of the following numbers is the largest?

$-0,625 ;-4 / 10 ;-0,375 ;-1 / 2$

Answer:

2. How many $4.5 \mathrm{MB}$ pictures can be stored on a $1 \mathrm{~GB}$ disc? $(1 \mathrm{~GB}=1024 \mathrm{MB})$

Answer:

3. A kilogram of cheese costs $£ 15.50$. How much does $700 \mathrm{~g}$ of cheese cost?

Answer:

4. A product is on sale. According to the label, the normal price is $£ 125$. The sale price is $£ 100$. What percentage of discount has been applied?

Answer:

5. A cookie contains $20 \%$ butter. Write as a fraction the part of the cookie that is not butter. Your answer should be expressed in its simplest form.

Answer: 
6. The cost of a product is $£ 36$. There is a special offer on at the store: "Buy two and you get the second at half-price". If you did buy two, what would be the cost of each product?

Answer:

7. Which prime number can be made by subtracting two multiples of 7 ?

Answer:

8. For the following expression to be correct, which number should replace Q? $\mathrm{Q} \times \mathrm{Q}=3 \times 3 \times 7 \times 7$

Answer:

9. What is the next number in the series $n^{2}: 1,4,9,16, \ldots$

Answer:

10. Imagine you are building a brick wall. The sequence of images shows the first stages of the construction.

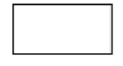

Stage 1

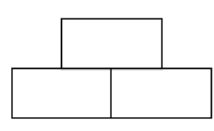

Stage 2

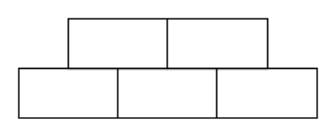

Stage 3

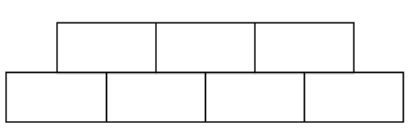

Stage 4

How many bricks will be in the wall in Stage 74 ?

Answer: 
11. When preparing an omelette, Lewis uses 2 egg whites and 1 yolk. To make a bowl of custard Nora needs 6 yolks. How many omelettes does Lewis have to prepare for there to be enough spare yolks for Nora to make a bowl of custard?

Answer:

12. This graph shows the position of two objects (a and b) over the time. Are either of the objects stationary? If so, which one?

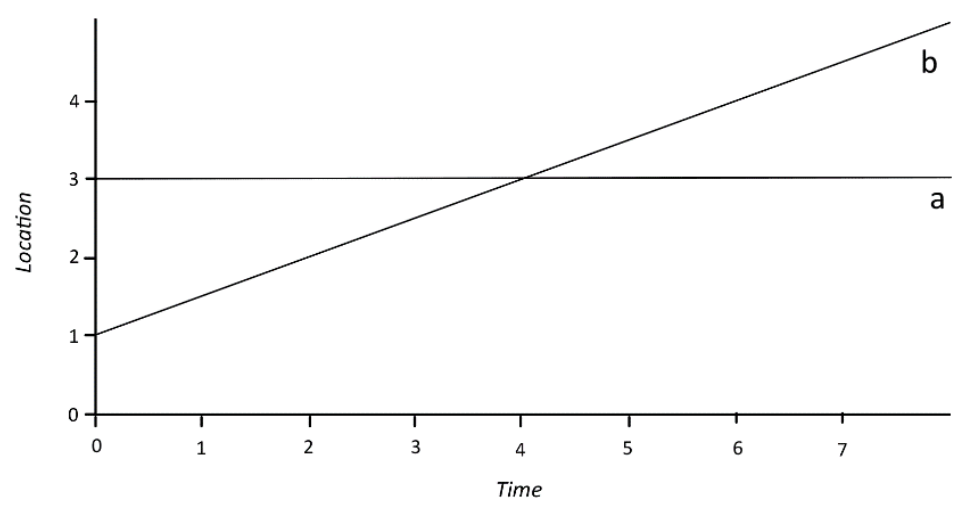

Answer:

13. You have two boxes which contain the same amount of sweets. In one of the boxes there are 2 bags of sweets and 3 single sweets. In the other box there is 1 bag of sweets and 8 single sweets. The amount of sweets in each bag is the same. How many sweets are in each bag?

Answer:

14. What is the surface area of a square with a perimeter of $32 \mathrm{~cm}$ ?

Answer: 
15. How much is a half of a half of a half? Draw it using the square below and then write the resulting fraction.

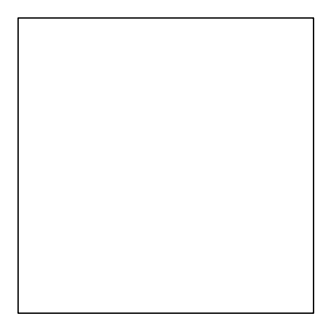

Answer:

16. Which of the following figures must have equal diagonals?
A. square
B. rhombus
C. rectangle
D. trapezium

Answer:

17. The figure on the left is a plane view of the object on the right.
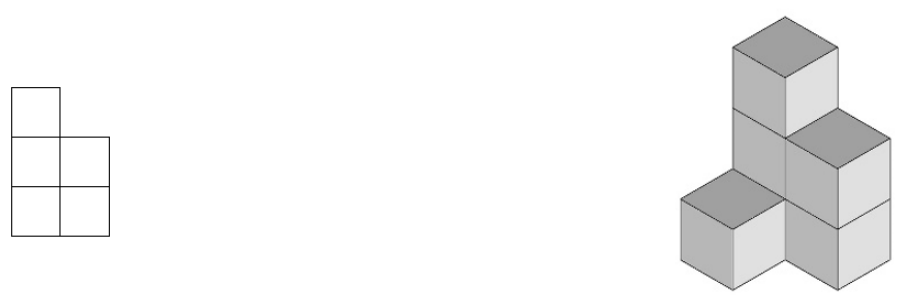

Knowing there are no hidden cubes, which of the following figures are also a plane view of the object?

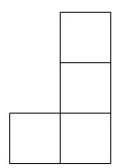

A



B

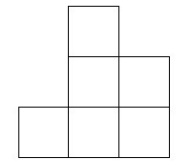

C

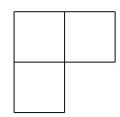

D

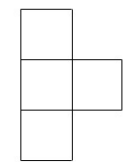

E

Answer:

18. How many $\mathrm{cm}$ are in $7.8 \mathrm{~km}$ ? 
Answer:

19. How many minutes are in 2.5 hours?

Answer:

20. What is the length of the thick black line?

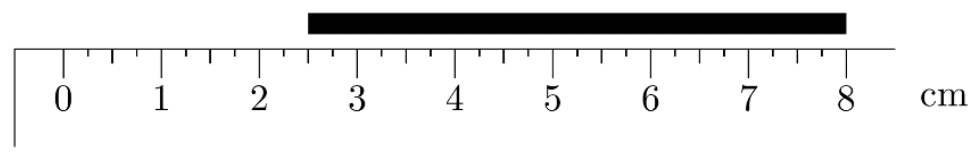

Answer:

21. What is the area of the shape below?

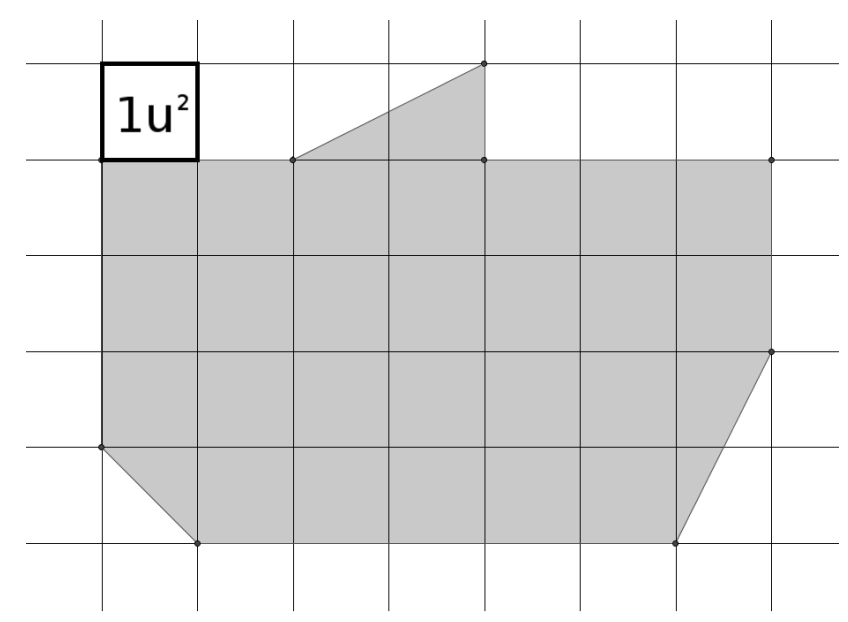

Answer:

22. Use the graph below to answer the following question. 


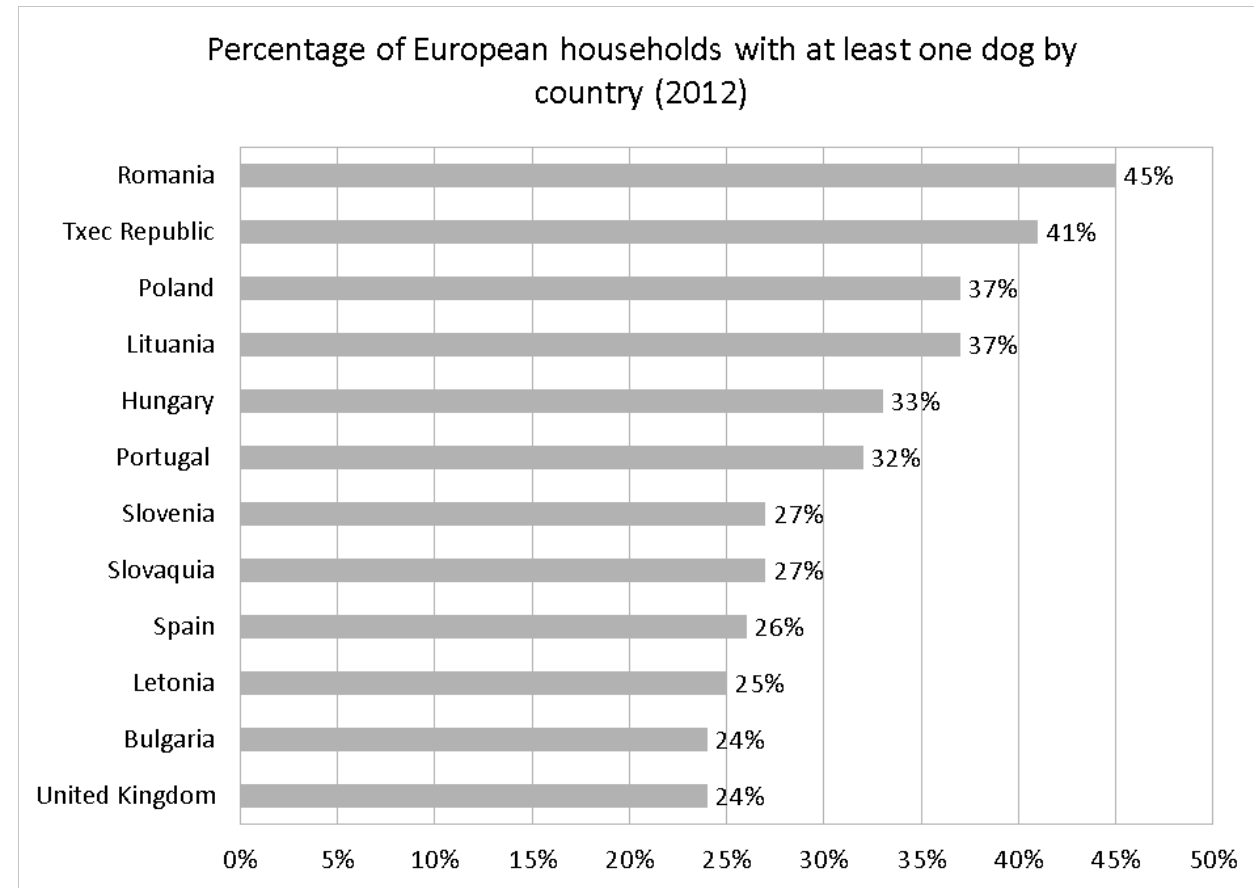

How many percentage points separate Lithuania and Romania?

Answer:

23.80o people took part in a survey concerning the number TV sets per household. The following pie chart shows the results of the survey.



How many people participating in the survey had 1, 2 or 3 TV sets?

Answer:

24. What number would we add to the list below in order for the mean to equal 7 ? 
$\{2,6,7,7,8,8,9\}$

Answer:

25. Create a bar chart using the data given in the table below.

Occupation by sector

\begin{tabular}{|l|c|c|c|}
\hline & 2005 & 2010 & 2015 \\
\hline Agriculture & $15 \%$ & $10 \%$ & $5 \%$ \\
\hline Industry & $35 \%$ & $30 \%$ & $35 \%$ \\
\hline Services & $50 \%$ & $60 \%$ & $60 \%$ \\
\hline
\end{tabular}

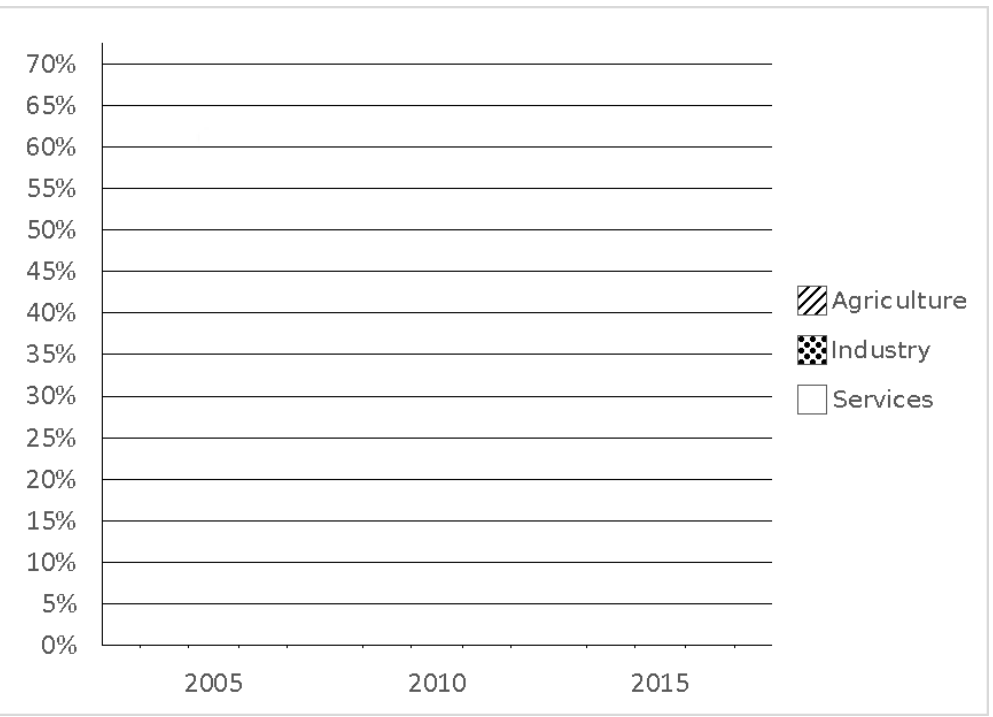

